ON THE POVERTY OF A PRIORISM: TECHNOLOGY, SURVEILLANCE IN THE WORKPLACE AND EMPLOYEE RESPONSES

\author{
David Mason ${ }^{1}$, Graham Button $^{2}$, Gloria Lankshear $^{1}$ and Sally Coates ${ }^{1}$ \\ University of Plymouth ${ }^{1}$ and Xerox Research Centre Europe, Cambridge \\ Laboratory $^{2}$ and Wes Sharrock ${ }^{3}$, University of Manchester ${ }^{3}$
}




\section{ON THE POVERTY OF A PRIORISM: TECHNOLOGY, SURVEILLANCE IN THE WORKPLACE AND EMPLOYEE RESPONSES}

\section{Introduction}

It has become a commonplace, but no less true for that, that the literature dealing with new electronic technologies of all kinds is replete with varying degrees of hype. Those who see ever more sophisticated ICTs as the key to a human future characterised by choice, freedom and plenty have all too often exaggerated the actual capabilities of the systems they promote, while downplaying or ignoring their negative impacts. Often, of course, there are powerful commercial motivations for such claims but journalists, politicians and academics have frequently been guilty of taking them uncritically at face value.

At the same time, these developments can be, and are, portrayed in fundamentally negative terms as a threat to individual privacy, autonomy and freedom if not actually spelling the end of embodied social life itself. These perspectives are, perhaps, less frequently driven by commercial motives, although anyone who uses the internet is daily bombarded with advertisements warning of threatened privacy and offering a range of technical solutions. More characteristically, doom-laden prognoses emanate from a range of libertarian, anarchist and left wing political positions. Once again, they are often uncritically endorsed and reproduced by a range of social commentators, journalists and academics, not all of whom necessarily share their underlying political perspectives.

At one level, this is scarcely surprising since the matters at stake go to the heart of some of the key assumptions and principles of liberal democracy and its left wing 
challengers. The debate is not simply about what are the demonstrable effects of the deployment of ICTs. It is also about the future potential of such systems and about the motives of those who design and deploy them. These must, perforce, be matters of speculation, however well-informed, and debates about them will inevitably be shaped by competing Weltanschauungen, hopes and aspirations as well as by predispositions to optimism or pessimism.

At another level, however, we are, perhaps, justified in registering disappointment, if not surprise, that the academic literature itself frequently falls victim to a similarly uncritical rehearsal of one or other position. Nowhere is this clearer than in the case of discussions of the impact of ICTs at work. Here, the obligation to adopt a 'critical' position is all too often code for enlistment to a perspective on the nature of the employment relationship which has dominated traditional industrial sociology, at least in Britain, and which owes its main features to an ongoing dialogue with Marxist class analysis. Frequently it seems that the only alternative to a wholehearted embrace of this perspective is an endorsement of managerialist accounts that are uncritical, in both the senses we have used that term.

There is no doubt that British industrial sociology has, over an extended period, yielded a wealth of rich and insightful studies of the nature of the employment relationship in capitalist societies. Classics like Lupton's On the Shop Floor (1963) and Beynon's Working for Ford (1973) are only two examples of a genre that has been latterly enriched by the feminist scholarship of writers such as Sallie Westwood (see her All Day, Every Day, 1984). Whether or not one accepts the various theoretical assumptions against which these analyses are framed, it is clear that they are based on the interrogation of detailed empirical data. Yet more recent discussions of the impact of 
ICTs at work, while often framed by similar theoretical and political assumptions to older studies, all too frequently lack an equivalent level of explicit empirical underpinning, as Bain and Taylor's critique of the literature on call centres eloquently demonstrates (2000). These features are particularly prominent in the increasing number of discussions that focus on workplace surveillance.

It is against this background that we offer the arguments presented in this paper. Our contentions are essentially threefold. First, we argue that the relative paucity of empirical studies of the impact of ICTs on the social relations of work makes many discussions fall victim to hype and to the uncritical embrace of a priori assumptions that obfuscate as much as, if not more than, they illuminate. Second, we contend that the dominance of a particular set of a priori assumptions associated with the labour process tradition artificially restricts the range of perspectives represented in the literature. Third, we argue that taking seriously actors' own accounts, without filtering them through the lens of such a priori theoretical assumptions, permits the emergence of alternative perspectives on the impact of ICTs at work that are rooted in the day to day experiences of actors.

In what follows, we offer a critique of the a priori assumptions that, we contend, characteristically frame discussions of workplace surveillance. We also present a number of findings from our own study of surveillance-capable technology in the workplace that, we suggest, offer some rather different perspectives on the social relations of work in such environments. We commence, however, by outlining the main features of the research project on which we draw. 


\section{The research}

The findings we report below derive from a research project designed to investigate how surveillance-capable technology impacts on, and is framed by, the social relations of work. ${ }^{1}$ The research was stimulated in part by the burgeoning academic interest in the increasing deployment in the workplace of a range of electronic technologies that have the potential to be used for the purposes of audit and monitoring. We characterise these technologies as surveillance-capable because, in the course of normal operation, they collect data on individual activities that are stored and thus become potentially available for surveillance purposes, whether or not anyone actually uses them with this objective. We should make it clear that we are not mainly concerned with 'surveillance technologies' in the sense of those that have been intentionally designed to undertake surveillance and monitoring functions. Instead we are concerned with a much larger class of electronic and communications systems that are increasingly part of the landscape of the modern workplace. Such surveillance-capable technologies range along a continuum. At one extreme are those that might have a primarily surveillance function (such as CCTV systems). ${ }^{2}$ At the other are systems that are designed with non-surveillance functions in mind (such as workflow control technologies) and where the capacity to monitor individuals' work is a by-product. In between are those where a surveillance or audit function has been intentionally designed in but where the relative emphasis on various system capacities is dependent on local needs and implementation strategies.

\footnotetext{
${ }^{1}$ Technology, Work and Surveillance: Organisational Goals, Privacy and Resistance (L132251036) - ESRC Virtual Society? Programme

${ }^{2}$ Even here it should not be assumed, however, that such systems are necessarily installed for disciplinary reasons. Thus CCTV systems may be intended to monitor customers' behaviour rather than that of employees, to manage access or to monitor safety.
} 
Our research was designed to address questions raised by the existing literature through an empirical study of ongoing social relations of work. We were concerned with such questions as: whether and how employers deploy surveillance capacity; how employees define the boundaries of legitimate and illegitimate surveillance, particularly in relation to issues of privacy; and how they perceive and mobilise techniques of control and/or resistance in the context of definitions of legitimacy. A series of case studies of different work situations was undertaken with the aim of revealing how the individual responses and social adaptations of both employers and employees arose from situationally specific perspectives, located in the day to day activity of work. Research sites included: a print shop utilising workflow management technologies; a public health laboratory using a computerised reporting system; a council tax office utilising a computerised billing system; two call centres deploying computerised call management systems and audio monitoring technologies; a power station utilising a range of relevant technologies including swipe card entry, CCTV monitoring and a computerised management information system. In addition, a cord blood gas analysis system and a computerised instructional package in a maternity hospital environment were also studied and information was generated about an instance of E-mail monitoring in a university. Finally, we undertook a mail survey of trades unions with the aim of determining determine the scale of employee concern about privacy issues, as measured by the frequency with which these matters were the subject of member complaints.

Although the precise details and sequencing of work undertaken varied between case study sites, a wide range of ethnographic techniques was utilised. These included observation, semi-structured interviews with employees and managers, documentary 
analysis and, in some cases, brief orienting questionnaires. The duration of fieldwork also varied between sites, partly as a result of varying access conditions and partly in response to emerging research questions and opportunities. The most extended periods of observation, ranging over between three and eighteen months, were conducted in the two call centres studied, in the maternity hospital, in the public health laboratory and in the print shop. These sites yielded some our richest data and their significance for our overall findings is reflected in the manner on which they are drawn in what follows. Interviews were tape recorded and transcribed, and data deriving from this source, together with observational fieldnotes and other textual data were analysed using NUD*IST 4. Where available, visual data, including photographs and video recordings, were used to support the analysis.

\section{A priori assumptions and the debate about workplace surveillance}

In much management discourse, technological innovations of the kind we are concerned with are represented as empowering, enhancing the capacity of individuals to contribute to individual and organisational goals. By contrast, however, most social science, and many lay, responses to these developments have been framed within one or more rather different sets of assumptions. The first suggests that technological developments exercise decisive influences over the way in which organisations function and develop. This essentially determinist position assumes that the very availability of a technological capacity will lead to its deployment and that this, in turn, will transform the way the organisation functions. The second set of assumptions concerns the nature of the employment relationship itself. Here it is assumed that the workplace can be characterised as one of struggle and conflict and that relations between management and employees are intrinsically oppositional. In such a model, the logic of management as control makes the deployment of the enhanced surveillance capacity of technology 
inevitable. When put together, these sets of assumptions give rise to a debate about the degree to which employees are able to resist the managerial consequences of enhanced surveillance capacity.

Perhaps the seminal paper in initiating this debate was Sewell and Wilkinson (1992). They highlighted the apparent paradox that modern developments in the labour process and managerial strategies have given rise to decentralisation and devolution of responsibility for tactical decision-making while at the same time generating higher levels of centralised, strategic control and surveillance. This, they argued, was a necessary consequence of the disruptive potential acquired by empowered employees in devolved systems. Put another way, Sewell and Wilkinson were claiming that, despite apparently radical changes in the organisation and management of work, management retained, and continues to pursue through new means, its traditional interest in challenging worker empowerment and autonomy.

Sewell and Wilkinson's paper, in its turn, gave rise to a further debate within the labour process literature about the extent to which such systematic disempowerment was inevitable and ubiquitous or, to the contrary, was capable of resistance. Thompson and Ackroyd (1995), for example, accused Sewell and Wilkinson of overdrawing the power of the 'electronic panopticon' (cf. Webster and Robins, 1993: 244). They argued that, while Sewell and Wilkinson might be correct in their diagnosis of organisational trends and managerial strategies, they were wrong to underestimate the scope for, and the level of, worker resistance. They called for a return to the traditional focus of industrial sociology on employee resistance to ever-changing strategies of managerial control. 
Despite their differences, both these positions share the fundamental assumption that the employment relationship is intrinsically exploitative, oppositional and essentially conflictual. This assumption is widespread in the sociology of work - or what used to be called industrial sociology - and fundamentally structures how the actions of managers and employees are interpreted. Thus, for example, Edwards argues that, '[S]ince conflict is structured into any employment relationship, a pattern of workplace relations cannot dissolve this conflict' (1988: 195). In other words, even when employees behave in ways that appear to run counter to the assumption, the basic or underlying condition is held, in reality, to frame their actions. The contrast is frequently handled by invoking the concept of contradiction, as when Edwards claims that workplace relations 'have a contradictory character: they simultaneously reflect workers' efforts to exert their control and an accommodation with, and indeed often an active pursuit of, organisational rules' (1988: 188). It is arguable, however, that this situation is only contradictory if we accept the initial assumption in terms of which it is framed. It is equally plausible to suggest that when workers display varying responses to 'organisational rules', this may merely reflect judicious responses to different rules and different situations.

Interestingly, both sides of the debate discussed above are faced with difficulties that arise directly from their mutual endorsement of assumptions about the nature of the employment relationship. Proceeding from the a priori assumptions we have described necessarily entails the search for instances of resistance or the identification of circumstances where, but for the subduing effects of panoptic surveillance, resistance would have been anticipated. But this leaves open the question of what is to count as 'resistance'. When we examine this issue, however, we find that the use of the description 'resistance' with respect to workplace activities is characteristically undiscriminating. There is no standard basis on which instances of resistance are 
identified. The criteria are varied, and are variable in their application. As a result, the assortment of examples of resistance described in literature is very wide ranging. They vary from what are presumptively acts of defiance (such as refusing to wear company uniform or ostentatiously paying no attention at team briefings) (Delbridge, 1995: 813) to self-defence against the risk of disciplinary measures (such as passing inferior work to prevent the generation of significant amounts of wastage) (Webb and Palmer, 1998: 617). Other practices are offered as examples of resistance, though it is difficult to equate them with either of these extremes. They include situations where workers depart from the strict requirements of procedures - for example, developing 'shortcuts' which do not follow 'the work standard to the letter' (Webb and Palmer, 1988: 622), the substitution of poor work to save effort and the 'misuse' of the 'clearing up' period (Webb and Palmer, 1998: 620). Sometimes, it is apparently even 'difficult to identify' (Delbridge, 1995: 812) instances. Yet the presumption is that they must exist or, at least, be attempted. ${ }^{3}$

Not only is there a lack of consistency with respect to the examples offered as resistance there is, too, a distinct lack of proportion in the categorisation of activities. The term 'resistance' itself is endowed with a strategic ambiguity, one which enables it to

\footnotetext{
${ }^{3}$ We are not arguing, it should be clear, that resistance is not a common occurrence within workplaces. We are, however, questioning the helpfulness of a theoretical predisposition to seek out and find resistance in all aspects of worker behaviour. We would also suggest that this concept requires a much more fine-grained specification if it is to be analytically helpful. The cover description of Jermier et al. (1994) is revealing in this regard. The question is posed whether '...conflict and struggle at work [are] as normal as compliance and consent...' In fact, the contents of the volume offer few, if any, examples of the latter pair while giving the impression that only the former are normal.
} 
sound as though it captures a strong, determined and explicit rejection of managerial domination, while it is deployed as an expression with a merely technical content, identifying merely those actions which happen - in one way or another - to deviate from management expectations (Edwards, 1988). ${ }^{4}$ The instances of such deviation cited in the literature are seldom of a kind that would cause disruption of work productivity on a scale that even the literal 'spanner in the works' could often accomplish. They are, as Edwards recognises, acts which 'do not affect total production and are largely neutral as far as managerial interests are concerned' (1988: 191). Thus, the fact that people let items pass quality inspection on the ground that there is a flaw which is so slight that it will not, in all probability, be noticed by the customer, or that workers 'make time' by pacing their work through the use of 'shortcuts' are not, of themselves, matters which can be alleged to make much, if any, material difference to management. Unless the 'management interest' is assumed to lie in complete control of all details of employee conduct, then allowing slight faults through quality inspection is hardly a significant - it is not even a discernible - assault upon them. ${ }^{5}$

\footnotetext{
${ }^{4}$ Resort to the term 'fiddles' is used as an alternative, carrying connotations of less overt and more evasive responses, but even this is no more clearly defined.

${ }^{5}$ It might be argued that in total quality systems, often said to be characteristic of Japanese managed companies, management might be said to have an interest in preventing the concealment of productive 'fiddles' in order to learn from them. Even here, however, studies of 'Japanisation' collectively suggest what should not come as all that great a surprise: that neither UK managers nor workers necessarily pursue just-in-time production or total quality methods with the rigour and enthusiasm that (it is alleged) the originators of these systems do or with quite the rigour that the systems might ostensibly require (cf. Webb and Palmer, 1998).
} 
In short, then, there is a widespread tendency to characterise all apparently noncompliant acts by employees as resistance aimed at asserting control contra management interests or requirements and at protecting individual privacy and autonomy. However, much of the debate is conducted at the level of speculation rather than in terms of detailed empirical evidence. It was against this background that the research project, the results of which are reported here, was conceived. It was framed by an initial assumption that all social (and by extension technological) developments are potentially Janus-faced in their implications and that only detailed empirical investigations can uncover how they play out in practice.

\section{Technology, surveillance and the social relations of work - some findings}

By contrast with the compliance/resistance couplet offered by much of the literature, our work suggests that the response of employees to technology, and to the management structures within which it is deployed, is much more complex. This is because, we suggest, employers and employees are caught up in complex social relations of work within which technology is variously deployed, struggled with, sidelined, manipulated, circumvented and appropriated.

\section{Circumventing technology 1: resistance or compliance?}

The first point to note is that, in practice, technologies often fall short of the expectations of those who designed or installed them. Our research revealed a number of cases in which employees and managers were faced with systems that failed to deliver the benefits promised. In some instances, planned implementations either did not go ahead to schedule or extensions of use were abandoned or suspended. In the Council Tax office, for example, we encountered a newly introduced computerised record and billing system that was designed to streamline the processing of Council Tax registrations and 
payment demands. In addition, however, the implementation of the system was also intended, in part, to operate as a trial for the projected extension of the system to other Council departments, including the higher work-volume environment of a benefits office. In the event, however, difficulties in making the system work effectively led to a decision to defer a further roll-out beyond the lifetime of the research project.

In other cases, considerable individual and collective effort and ingenuity was required to make the technology work. In such cases the technology was frequently subverted, circumvented or manipulated as managers and employees worked together in order effectively to achieve the organisation's goals. In such cases, it is important to note that employees characteristically identified overtly with those goals, frequently going beyond the call of duty to realise them. At the same time, managers often colluded with practices that broke the letter, and sometimes the spirit, of organisational rules in order to maintain the day-to-day working relationships which made the achievement of organisational goals possible. Thus, in the print shop studied, employees (in collusion with management) found ways to circumvent a workflow management system which not only changed the way they worked but actually made the task of meeting production targets more difficult. In re-establishing former patterns of work organisation, employees were not resisting management control nor simply seeking to reassert a lost autonomy. Rather they were seeking to re-establish a method of working which actually met organisational goals more effectively.

A similar point is made by the case of a computerised instructional tool designed to improve the capacity of staff to interpret the data output from patient monitoring systems in a maternity hospital. In order to use the system, staff logged in with a personal identification number (PIN). As the system was used, it generated a record that 
included time and duration of use as well as the scores obtained in a number of simulation exercises. Data generated by this monitoring capacity had been used as part of the system's design and evaluation. However, at the time of the research, its deployment for surveillance purposes was inhibited by the fact that staff would routinely 'borrow' others' PINs - effectively their identities. As a result, it was impossible to know from which staff members the recorded data derived. While it would be easy to see this as an example of resistance, interview data suggest other explanations. In the pressurised working environment of the maternity ward, time for training activities was at a premium. Respondents who professed themselves keen to use the system during lulls in their work told us that they were inhibited from doing so by the need to find time to get themselves issued with a PIN. In these circumstances, it was easier simply to 'borrow' someone else's identity in order to snatch a few minutes on the system and this is what at least some of them did. That it was felt necessary and appropriate to do so appeared itself related to midwives' commitment to providing the most high-quality care for patients. As one respondent put it:

I am delighted to do the package. I can only see advantage in it for me. I have a responsibility to be competent. I need to know what that information means.

It is not difficult to see how the actions of employees in the cases described above might be said formally to meet the definitions of resistance outlined above. At the same time, they vividly illustrate how unhelpful such a characterisation of employee behaviour would be. Nor does it make much sense to categorise such actions as compliance, as if employees simply and uncritically acquiesced in management demands. Indeed, to have done so would have ensured that new systems not only failed but also disrupted work in the process. In other words, it would have been the 
most effective form of resistance available, were this what employees were seeking to achieve. Instead we suggest that what happened in these situations only makes sense in the context of the social relations of work that characterised each of these workplaces. Of course, in each and every case, those workplaces themselves were set within wider social contexts. Some aspects of what occurred within them had their origins outside the immediate environs of work. Both employee and management behaviour depended in part upon demands and understandings originating elsewhere. To recognise this is not, however, to accede to the proposition that every aspect of the social relations of work in actual workplaces can be understood in terms of conceptual categories deriving from high level theoretical generalisations about that wider context.

\section{Circumventing technology 2: resistance or appropriation?}

Not every example of the circumvention of technology can be understood as an attempt to make ill-designed or inappropriate systems work effectively. Sometimes, employees oriented to systems in ways that, at first sight, more readily fit the category 'resistance' as it appears in the literature. Certainly, in some instances, it would be difficult to characterise employee behaviour as in any sense in line with either the design features of systems or the implementation strategies of managers. Even here, however, we contend that the gross category 'resistance' provides little analytic purchase on the variety of actions and motives encountered among employees. In particular, we found many instances where employees appropriated the technology in order to achieve a variety of individual and collective goals. For example, some respondents saw the apparently objective and auditable data produced by technological monitoring as a protection against unfair work distribution or accusations of dereliction. Such data appear more disinterested than the potentially arbitrary judgements made by managers engaged in traditional modes of work observation and monitoring. The greater 
'warrantability' of these data provides a powerful, 'scientifically' validated, source of evidence to which employees themselves can appeal. As one respondent in the Council Tax office, commenting on the system's potential for ensuring a fair distribution of work and highlighting effort, put it:

If you have not got anything to hide then there is no problem with it. That is my opinion on it. Not that we have a problem with it anymore but there always used to be times when people weren't pulling their weight. Now that would be highlighted.

Here, as in the call centres studied, employees utilised the surveillance features of systems to demonstrate that they were working in a manner that met or exceeded management expectations. In one of the call centres studied, they also used publicly visible electronic displays, registering various features of individual performance, variously to manage their own work rates, come to the assistance of colleagues, or ensure that they made optimal use of permitted rest time (Lankshear et al. 2001).

Moreover, even where employees initially opposed the introduction of monitoring, hostility often abated as fears were allayed and staff appropriated the technology to their own purposes. A good example of this process at work was encountered in the power station studied. Here, the twenty four hour operation of the plant required that maintenance personnel be able to access spare parts and tools at all times. The stores, however, were not staffed at night. Those requiring items during this time were required to sign out any equipment or materials taken. In practice, this did not always happen, with the result that the inventory was often inaccurate, leading to a failure to reorder vital items. (There was no explicit suggestion that theft or other illegitimate removal of 
materials was a concern.) In order to address this, management installed CCTV cameras in the stores area with the aim of producing a record of its use when unstaffed. The initial reaction of stores staff was hostile. They were concerned either that they were suspected of impropriety or that the system could be used to monitor their activities when on duty. Management sought to allay these fears but the opinion of stores staff was finally swayed when they realised that they could recruit the system to their own purposes. Because the system monitored the counter area, where 'customers' would arrive to seek items (or to sign them out at night), it generated an opportunity for stores staff to deploy their time more effectively. Thus instead of having constantly to be present at the counter, they were able to undertake other tasks, in other parts of the stores, relying on the CCTV monitors to alert them to the presence of 'customers'. This example also shows how even technologies which had overt surveillance functions evoked responses which, while exhibiting some of the features of 'resistance', might best be described as 'putting the technology in its place', as recourse was made to humour and the technology recruited to episodes of playfulness. The response of one employee to the introduction of the CCTV system in placing a large paper bag over his head whenever he entered the stores area would seem best described in these terms.

\section{Reinstating the social in relations at work}

Conceptualising the multi-dimensionality of the social relations of work

A key finding of our research was that the relationship between technological innovation and the social relations of work could not be properly understood if the latter were conceived only in terms of the relationship between employers and workers. Not only were relations among employees of crucial importance but there were also a number of cases in which one or both parties were also orienting to other significant players. A key example was where employees were involved in an interface with customers - or 
patients in the case of the instructional package discussed above. In these cases, it was difficult to understand key features of employee responses to electronic monitoring without taking cognisance of the significance of what was effectively a three-way social relationship.

In one of the call centres studied, employees' relationships with customers had implications for their responses to different kinds of management demands. They invoked the obligation to keep customers happy in order simultaneously to perform to managerial expectations in the quality of interactions with customers while simultaneously resisting management demands to become more sales-oriented. As a management respondent put it:

We've tried time and again to get them to sell and they won't do it. They do everything else we ask them to do, but they will not sell.

This example illustrates the weakness of the resistance/compliance couple. In this instance, the complex three-way social relationship between management, employees and customers created an organisational space in which employees could develop and defend their own definitions of 'professional' conduct, which involved striking a balance between corporate and client interests, and acting with a sense of ethical and personal autonomy. These definitions of professionalism and good performance are difficult to conceptualise either in terms of resistance or of compliance since they were neither at complete variance with, nor simple clones of, management definitions. We suggest that it is better to see them as a negotiated outcome of a situation in which both sides enjoyed relative, but restricted, autonomy. (For a fuller discussion see Lankshear et al. 2001) 
Another aspect of the multi-dimensionality of workplace social relations is highlighted if we recognise that neither 'managers' nor 'employees' constitute undifferentiated categories. Local managers, for example, often appeared more alive to the dysfunctional consequences of technological innovations than were those more senior and remote. This is a particularly important point given the increasing tendency for what were once called 'supervisors' (shop floor staff promoted to co-ordinating roles) to be renamed 'managers'. Such individuals may be particularly likely to be locked into forms of interaction with former peers that have significant implications for the performance of their functions. As a result of affective attachments, or perhaps of the internalisation of the discourse of 'team working', they manage others in ways that frequently depart from the strict letter of organisational policy. Thus they may exploit both personal connections and 'inside' knowledge to maximise productive effort. In other circumstances, they mitigate the impact of organisational rules on employees in ways that are oriented to a sense of mutual personal obligation without obvious productive payoff (see the discussion in Lankshear et al. 2001)

\section{Resisting individualisation}

A feature of almost all the technologies encountered in the research was the predication of their design on the presumption that work is an individual activity. Where the collective dimensions of work were recognised, this found expression in a view that saw the task of technology as aggregating and co-ordinating individual efforts to produce a collective outcome. Such a perspective fails, however, to recognise that what appears to be individual effort is itself frequently the outcome of collective and collaborative interactions. The overlooking by technology designers of this social dimension of work appeared frequently to account for difficulties encountered in implementation. In this 
context, many of the responses of employees (and indeed of managers) only make sense if they are seen as part of an attempt to re-establish the collective dimensions of work in the face of the individualising tendencies of technology. The print shop provides a prime example of this point. Prior to the introduction of the workflow management system staff had routinely shared work, watched others' machines and swapped tasks in order to optimise both their own efforts and the flow of work though the plant. The workflow management system, by contrast, conceived the work of the print room as a set of identifiable tasks which could be separated, timed and sequenced and operated by allocating particular 'jobs' to individual operatives. Because it individualised tasks that had previously been accomplished collaboratively it not only failed to deliver on its objectives, it also significantly disrupted production. The response of operatives in circumventing the system, and re-establishing the productive order of the print room, can be seen in large measure as consisting of the recovery of the collective character of work. This was accomplished by manipulating the input of data required by the system in a manner that misrepresented the actual flow of activity in the plant, while ultimately producing an auditable 'record' in line with the requirements of the system and those who had installed it.

\section{Compliance, resistance and competing legitimacy claims}

This last point draws attention to a key issue. This is that employees' responses to technological innovation, and the managerial regimes within which it was deployed, were framed by beliefs and expectations that had their origins both inside and outside work. The examples of the professional commitments of midwives, or of the development of a sense of professional responsibility among call centre operatives, are both cases in point. 
In this context, we should note that almost all employees in our case studies appeared to recognise, and indeed accept, that monitoring and surveillance was a routine aspect of their working lives. Few, if any, appeared wholly unaware of the surveillance capabilities of systems they used while many more saw them as little more than an extension of traditional forms of monitoring. There was a widely expressed acceptance of the legitimacy of such monitoring, not only where there were perceived problems but more routinely. As one call centre agent interviewed put it, 'If you are going to have their wages then I suppose you have to work to what they want.' In contrast to the concerns of much of the literature and a good deal of public discussion, ${ }^{6}$ there is little evidence in our research of employees regarding technological surveillance systems as a threat to privacy. Not only did almost no respondents in our study express such concerns but a mail survey of trades unions (followed up by a number of interviews) suggested that concerns of this kind were not widespread. Unions reported few complaints from members and, while they remained wary of future developments, generally appeared to accept monitoring of work performance, as well as for security purposes, as legitimate. A prime concern, however, was that such activities should be open, subject to collective agreement and conducted within the law (compare Ford, 1998). Providing these conditions were met, the potential for a mutual benefit was recognised. Often initial concerns had been allayed following experience of implementation and early opposition sometimes turned to support. In some cases, surveillance systems had been used to address questions of concern to unions and their

\footnotetext{
${ }^{6}$ See for, example, the following press articles: Barnett, 2000; Bresler, 2000 a \& b; Inman, 2000. For a contrary view more in line with the findings reported in this paper, see Sinclair, 2001.
} 
members as, for example, when monitoring of E-mail was used to trace those responsible for abusive or indecent postings.

Only in two cases did respondents express concerns about privacy in the context of electronic monitoring, and the manner in which they did so may indicate something about the way the distinction between privacy and legitimate monitoring is conceived more widely. In one of the call centres studied, there were no facilities for making or receiving private calls. When it was necessary for operatives to make or receive calls, therefore, they were constrained to use the Centre's main system. Although there was no suggestion that the monitoring of private calls was routine or an aspect of company policy, respondents exhibited great sensitivity about the possibility of accidental intrusion into private matters should such calls be caught up in the process of routine monitoring. The other issue raised by respondents in the same call centre was an objection to being asked to explain why they wanted time off when requests were made. In both cases, what is of interest is the clear distinction being made between illegitimate trespass into matters that were regarded as occupying the realm of personal privacy and legitimate monitoring of occupational performance or regulation of leave entitlement.

We have no way of knowing, of course, whether employees subject to more intrusive forms of surveillance than those in our case studies would have responded differently to such legitimacy claims. Nor can we know whether a right to privacy might have been invoked to counter levels of surveillance that were perceived as exceeding the boundaries of the acceptable or legitimate, even if they did not stray into the realm of the personal as defined by our respondents. The issue, however, highlights the way in which experiences at work, and values, beliefs and principles deriving from outside the workplace, are likely to interact in framing the legitimacy claims deployed by parties to 
the social relations of work. Certainly, the right to privacy is one that appears to be widely endorsed and celebrated in liberal democracies. It embodies strong legitimacy claims that are difficult to challenge without invoking principles that can claim a higher priority - such as public interest, security or child protection, for example. In these circumstances, we might have expected it to be more widely deployed were the social relations of work in our research sites framed in terms of the fundamental and intrinsic oppositions suggested by much of the literature reviewed earlier in the paper.

\section{Conclusion}

We have argued that the framing of debates about surveillance at work within a set of a priori assumptions about the nature of the employment relationship greatly inhibits our capacity to understand the complexity of employee responses to the spread of new technology at work. In particular, the debate about the prevalence of resistance is hamstrung from the outset by the assumption that all apparently non-compliant acts, whether intentional or not, are to be counted at acts of resistance.

We have argued, instead, for greater attention to be paid to the empirical character of the social relations at work in and through which technologies are deployed and in the context of which employee responses are played out. In particular, we have suggested the resistance/compliance couple is too blunt an analytic instrument to capture the richness of those social relations. We have suggested that there is an urgent need to reinstate the social in analyses of workplace relations just as we have argued that our respondents frequently found themselves struggling to reinstate the social dimensions of work in the face of individualising technologies. 
At the same time, we have argued that all parties to working social relations bring with them to the workplace understandings and definitions of legitimacy that have their origins at least partly outside the world of work. These definitions of legitimacy exercise a powerful influence on how employees respond to different aspects of technology and the management strategies through which it is operationalised. Nowhere is this clearer than in the context of privacy where our respondents' expectations and understandings diverged significantly from those to be found in much academic literature and social commentary - itself frequently framed in terms of a range of a priori assumptions about the priority attached to privacy at work.

\section{Acknowlegement}

We are grateful to participants in the ESRC funded seminar: Privacy, Surveillance, Trust and Regulation, University of Edinburgh, March 9-10, 2000, for their comments on an earlier version of this paper 


\section{References}

Bain, P. and Taylor, P. (2000) ‘Entrapped by the "Electronic Panopticon”? Worker Resistance in the Call Centre', New Technology, Work and Employment, 15 (1): 218.

Beynon, H. (1973) Working for Ford, London: Allen Lane

Barnett, A. (2000) The end of privacy, The Observer, 30 July p.21

Bresler, F. (2000a) Send the wrong e-mail and you could be fired on the spot, The Times, 15 November, Creme p.4

Bresler, F. (2000b) Human rights at work The Times, 22 November, Creme p.4

Button, G., Mason, D. and Sharrock, W. (forthcoming) Disempowerment and Resistance in the Print Industry? Reactions to Surveillance-Capable Technology. New Technology, Work and Organisations, Vol. 18(1), 2003

Cressey, P. and Mclnnes, J. (1980) 'Voting for Ford: industrial democracy and the "control of labour"', Capital and Class, 11, 5-33

Delbridge, R. (1995) 'Surviving JIT: control and resistance in a Japanese transplant', Journal of Management Studies, 32, 803-17

Edwards, P. K. (1988) 'Patterns of conflict and accommodation' in Duncan Gallie, (ed.) Employment in Britain, Oxford, Blackwell

Ford, M. (1998) Surveillance and Privacy at Work, London: The Institute of Employment Rights

Inman, P. (2000) Email? You've got the elbow, The Guardian, 25 November Jermier, J., Knights, D. and Nord, W. (1994) 'Resistance and power in organisations: agency, subjectivity and labour process' in Jermier, J., Knights, D. and Nord, W., Resistance and Power in Organisations, London: Routledge 
Lankshear, G. and Mason, D.(2001) 'Technology and ethical dilemmas in a medical setting: privacy, professional autonomy, life and death', Ethics and Information Technology, 3(3), 2001, pp. 225-235

Lankshear, G., Cook, P., Mason, D., Coates, S. and Button, G. (2001) 'Call Centre Employees' Responses to Electronic Monitoring: some research findings', Work, Employment and Society, 15(3), 595-605

Lupton, T. (1963) On the shop floor: two studies of workshop organization and output, Oxford: Pergamon Press

Nichols, T. and Beynon, H., Living with Capitalism, Routledge, 1977.

Sewell, G. and Wilkinson, B. (1992) "'Someone to watch over me": surveillance, discipline and the just-in-time labour process', Sociology, 26(2): 271-289

Sinclair, D. (2001) Is 'big brother' a myth? The Guardian, 15 March, Guardian Online Thompson P. and Ackroyd S. (1995) 'All quiet on the workplace front? A critique of recent trends in British industrial sociology', Sociology, 29(4): 615-633

Webster, F. and Robins, K. (1993) "'I'll be watching you": Comment on Sewell and Wilkinson', Sociology, 27(2): 243-252

Webb, M. and Palmer, G. (1998) 'Evading surveillance and making time: an ethnographic view of the Japanese factory floor in Britain', Work, Employment and Society, $10(2): 251-271$

Westwood, S. (1984) All day, every day: factory and family in the making of women's lives, London: Pluto Press 